\title{
Tricresyl Phosphate (TCP) Induced Polyneuropathy: Case Series from Dehgam, Gujarat, India
}

\author{
Solanki J ${ }^{*}$, Patel R', J agani DC', Raval D', \\ Yasobant $\mathrm{S}^{2}$ and Saxena $\mathrm{D}^{2}$ \\ ${ }^{1}$ Department of Health \& Family Welfare, Government of \\ Gujarat, India \\ ${ }^{2}$ Department of Epidemiology, Indian Institute of Public \\ Health Gandhinagar, India \\ *Corresponding author: Solanki J, Department of \\ Health \& Family Welfare, Government of Gujarat, India
}

Received: J anuary 02, 2017; Accepted: March 17, 2017; Published: March 27, 2017

\section{Abstract}

Background: Prevalence of polyneuropathy in the general population has been estimated to be $2.1 \%$ globally, with gigantic morbidities. One of the rare predictor is an organo-phosphate compound called Tricresyl Phosphate (TCP). In India, TCP exposure happens through traditional food preservation practices (i.e. Castro Oil with Wheat). Thus, this study aims to document the incidence of polyneuropathy and it's underneath factors in one of the block of Gujarat, India.

Methodology: After reporting of first case (July 2015) of Polyneuropathy, a snow ball sampling was adapted to identify the other possible affected families within $20 \mathrm{~km}$ of geographical radius in Dehgam. Followed which, active surveillance was conducted to identify all potential cases through house-tohouse investigation. Identified cases were investigated clinically and history of consumption was collected, followed by investigation of food samples.

Results: Until May 2016, about 50 cases were identified from 13 families of Dehgam block. Most of them complained about peripheral muscular pain along with immobility since last 2 months. The differential diagnosis report indicated no such identifiable predictors; hence food investigation was conducted. It has been found that most of them have TCP in their food, presented in the form of Castor Oil. The epidemiological distribution indicates that there were 27 males \& 23 females with mean age of $34.5 \pm 18.8,34.8 \pm 19.5$ years respectively.

Conclusion: This is unique kind of surveillance study where an inherent predictor of Polyneuropathy has been identified through community survey. In addition to this, TCP in food, a rare compound identified in this study need further investigations. There is an urgent need to develop a monitoring strategy along with appropriate IEC for reducing further burden.

Keywords: Polyneuropathy; Tricresyl phosphate; Surveillance; India

\section{Introduction}

Polyneuropathy is a peripheral neuropathy characterized by symmetrical sensory symptoms, such as numbness, paresthesia and pain, and muscle weakness, which are predominantly located in the distal parts of arms and legs. Polyneuropathy is a disabling disease and has a negative impact on a person's quality of life [1]. Although it is assumed that polyneuropathy affects a considerable proportion of the population, the exact prevalence and incidence of the disease are not well known [2]. Crude point prevalence of polyneuropathy in studies using this, or a similar protocol, ranged from 0.8 to 32.5 per 1000 $(0.1-3.3 \%)$ persons across all ages [2,3]. Several diseases and factors have been associated with polyneuropathy. Since polyneuropathy probably is a multifactorial disease, it is not entirely appropriate to attribute the development of polyneuropathy to only one factor. These factors should be considered as component causes, and not as one sufficient cause. Except diabetes and alcohol abuse; other known important causes of polyneuropathy include toxic agents, such as chemotherapeutic drugs, nutritional deficiencies, immune-mediated causes and hereditary factors [4].

Neurotoxic effects of Tri-Cresyl Phosphates (TCP) have been well recognized since the dramatic outbreak of "Ginger Jake Paralysis" which crippled as many as 50,000 in the U.S.A. in the 1930s [5]. Since then several other epidemics have occurred elsewhere, the outbreaks in Morocco [6], Durban [7] including in India Bombay [8] \& Calcutta [9], being some of the better known. In most instances poisoning occurred after consumption of edible oils accidentally contaminated or adulterated with mineral oils containing TCP. Because TCP is a widely used industrial chemical and is found in organic solvents and lubricating oils, it has always been a likely contaminant of food.

Therefore, this case series aims to document the incidence of TCP induced polyneuropathy and it's underneath factors in one of the block of Gujarat, India.

\section{Methods}

This case series [10] represents an observational study that reports on data from group of diagnosed polyneuropathy subject group without a comparison population. After reporting of first case (July 2015) of Polyneuropathy in one block (Dehgam) of Gujarat, a snow ball sampling was adapted to identify the other possible affected families within $20 \mathrm{~km}$ of geographical radius in Dehgam. Followed which, active surveillance was conducted to identify all potential cases through house-to-house investigation. Identified cases were investigated clinically and history of food consumption was collected, 
followed by investigation of food samples. Between July 2015 and May 2016; total of 50 polyneuropathy cases from 13 families were detected from this block and clinical/ epidemiological aspects are presented herewith. As there was unclear differential diagnosis history of food consumption and food sample investigation were carried out from the respective families.

\section{Clinical and epidemiological findings}

This case series consist of 23 females (46\%) and 27 males (54\%) from 13 different families with mean age of $34.8 \pm 19.5$ and $34.5 \pm 18.8$ respectively. The chief complain was peripheral muscular pain along with immobility since on an average last 2 months. Affected patients present with transient, painful "stocking-glove" paresthesia followed by a symmetrical motor polyneuropathy characterized by flaccid weakness of the lower extremities, which ascends to involve the upper extremities. Sensory disturbances are usually mild. Delayed neurotoxicity primarily affects distal muscle groups, but in severe neurotoxicity, proximal muscles groups may also be affected. Various clinical examinations reveal cases of polyneuropathy, with unknown etiology. These outbreaks may be due to a new or modified pathogen, a natural toxin, an initially undetected release of a chemical, or overexposure to ionizing radiation from an unknown source. Careful history taking and from this epidemiological study; researchers tried to point to one or more possible causes such as food toxicity, which provided a focus for further, more specialized investigation. Hence, food investigation was carried out from the affected families as well as from other families of field surveillance. It has been found that most of them have TCP in their food, presented in the form of Castor Oil. In every house almost all are affected those eat contaminated wheat mixed with castor oil. More than half (57\%) of food samples from affected families have shown TCP in their food investigation report, compared to only $15 \%$ in other surveillance families.

\section{Discussion}

In India, it has been estimated that $60-70 \%$ of food grains are stored at domestic level; whereas rest long term storage owned by the Food Corporation of India (FCI) and the Central \& State Warehousing Corporation (CWC/SWC) [11]. Proper storage of grains is essential to prevent infestation by stored product pests. Stored product pest management techniques followed by peasants are worth emulating. Evidences indicate that there are various methods adapted crossculturally to store the grains; as like aerial storage, storage on the ground or on drying floors, open timber platforms for temporary purpose and storage baskets made from plant materials, calabashes, grounds, earthenware pots, jars, solid wall bins and underground storage for longer period of time [12]. Out of these products, oils [13] from plant origin are one of them, which have been found to possess insecticidal properties are preferred with specific to Gujarat culture, where people mostly use Castor oil mixed in wheat, rice to store further. This case series found that TCP content in the use of castor oil from unidentified sources, which are available in local market with low cost. As per report of food and drug investigation; castor oil is non eatable food and it is not included in food safety and standard act 2006. Therefore, these traditional practices need to be worn-out from the community with appropriate Informed Education
\& Communication (IEC) programs and there is an urgent need to monitoring of these activities.

\section{Conclusion}

This is unique kind of surveillance type of case series, where an inherent predictor of Polyneuropathy has been identified through community survey. In addition to this, TCP in food, a rare compound identified in this study need to be an urgent call for action. There is an urgent need to develop a monitoring strategy along with appropriate IEC with inter-departmental co-ordination for reducing further burden. Further a follow-up study is recommended to understand the consequences of these TCP induced polyneuropathy cases.

\section{Acknowledgement}

We acknowledge to Department of Health Family Welfare, Government of Gujarat. We are also thankful near the participants for their time and kind cooperation.

\section{Funding}

This study has not received funding from any sources.

\section{References}

1. Teunissen LL, Eurelings M, Notermans NC, Hop JW, Van Gijn J. Quality of life in patients with axonal polyneuropathy. J Neurol. 2000; 247: 195-199.

2. Bharucha NE, Bharucha AE, Bharucha EP. Prevalence of peripheral neuropathy in the Parsi community of Bombay. Neurology. 1991; 41: 13151317.

3. Cruz Gutierrez-del-Olmo M, Schoenberg BS, Portera-Sanchez A. Prevalence of neurological diseases in Madrid, Spain. Neuro epidemiology. 1989; 8: 4347.

4. Hanewinckel R, Van Oijen M, Ikram MA, Van Doorn PA. The epidemiology and risk factors of chronic polyneuropathy. European Journal of Epidemiology. 2006; 31: 5-20

5. Morgan JP, Penovich P. Jamaica ginger paralysis. Arch Neural. 1978; 35: 530-532.

6. Smith HV, Spalding JMK. Outbreak of paralysis in Morocco due to orthocresylphosphate. Lancet 1959; 2: 1019-1021.

7. Susser M, Stein Z. An outbreak of Tri-Ortho-Cresyl Phosphate (TOCP) poisoning in Durban. Br J Industr Med. 1957; 14: 111-120.

8. Vora DD, Dastur DK, Braganca BM. Toxic polyneuritis in Bombay due to orthocresyl-phosphate poisoning. J Neurol Neurosurg Psychiat. 1962; 25: 234-242.

9. Srivastava AK, Das M, Khanna SK. An outbreak of tricresyl phosphate poisoning in Calcutta, India. Food ChemToxicol. 1990; 28: 303-304.

10. Chan K, Bhandari M. Three-minute critical appraisal of a case series article. Indian Journal of Orthopedics. 2011; 45; 103-104.

11. Kiruba S, Jeeva S, Kanagappan M, Stalin I.S, Das SSM. Ethnic storage strategies adopted by farmers of Tirunelveli district of Tamil Nadu, Southern Peninsular India. Journal of Agricultural Technology. 2008; 4: 1-10.

12. Mishra A, Prabuthas P, Mishra HN. Grain storage: Methods and Measurements. Quality Assurance and Safety Crops \& Foods. 2012; 4: 136158.

13. Singh A, Khare A, Singh AP. Use of Vegetable Oils as Biopesticide in Grain Protection -A Review. J Bio fertil Biopestici. 2017; 3: 114
Austin J Public Health Epidemiol - Volume 4 Issue 1 - 2017

ISSN : 2381-9014 | www.austinpublishinggroup.com

Solanki et al. (C) All rights are reserved
Citation: Solanki J, Patel R, Jagani DC, Raval D, Yasobant S and Saxena D. Tricresyl Phosphate (TCP) Induced Polyneuropathy: Case Series from Dehgam, Gujarat, India. Austin J Public Health Epidemiol. 2017; 4(1): 1057. 